\title{
POSIBLES PROBLEMAS EN LA INTERVENCIÓN DE LAS COMUNICACIONES EN ESPAÑA
}

\author{
Alejandro Villanueva Turnes \\ doi: 10.18543/ed-63(2)-2015pp263-281
}

\begin{abstract}
Sumario: 1. Introducción. 2. Titulares del Derecho al SECRETO DE LAS COMUNICACIONES. 3. PROBLEMAS A LA HORA DE INTERVENIR LAS COMUNICACIONES. 4. VULNERACIÓN DE UN DERECHO FUNDAMENTAL. 4.1. Secreto de las actuaciones en el proceso penal. 4.2. Descubrimientos ocasionales. 4.3. Secreto entre abogado y cliente. 5. RECAPITULACIÓN. 6. CONCLUSIÓN. 7. BIBLIOGRAFÍA 8. JURISPRUDENCIA.
\end{abstract}

«Todas las verdades son fáciles de entender, una vez descubiertas. La cuestión es descubrirlas».

Galileo

\section{INTRODUCCIÓN}

La Constitución Española de 1978 protege entre sus derechos y libertades fundamentales, el derecho a la inviolabilidad de las comunicaciones, más conocido como el derecho al secreto de las comunicaciones. Este derecho se encuentra regulado en el artículo 18.3 de la Carta Magna, el cual establece literalmente que: «se garantiza el secreto de las comunicaciones y, en especial, de las postales, telegráficas y telefónicas, salvo resolución judicial».

La inclusión de este Derecho dentro de la Sección Primera de Capítulo II, del Título Primero, intitulada «de los derechos fundamentales y libertades públicas», supone que el Derecho al secreto de las comunicaciones, junto con el resto de los derechos de esta sección, están altamente protegidos desde el punto de vista constitucional. Esta protección se concreta en que su desarrollo 
legislativo únicamente puede hacerse mediante una Ley Orgánica, sabiendo también que contaran con un procedimiento preferente y sumario en los casos en los cuales se hayan vulnerado, y que además de ello, hablamos de derechos susceptibles de recurso de amparo ante el Tribunal Constitucional, tal y como establece el artículo 53 de la Norma Superior del ordenamiento jurídico.

Junto con esta protección dada por la Constitución a estos derechos, también nos encontramos con que en caso de querer reformarse alguno de los artículos referidos a los derechos fundamentales, la Constitución va a exigir que se siga el procedimiento de reforma agravado, de tal manera que se puede ver como el Constituyente de 1978 quiso proteger al máximo estos derechos dándoles todas las protecciones que eran posibles.

Por lo que se refiere al derecho que nos ocupa, puede observarse como con anterioridad a la elaboración de la Constitución Española actual, ya encontraba una protección a nivel internacional donde quedaba manifestada su importancia, por lo que dicha regulación es un pilar importante a tener en cuenta que ha influido claramente en los distintos ordenamientos jurídicos, incluido el español. Así, esta regulación a nivel internacional puede encontrarse en primer lugar en el artículo 12 de la Declaración Universal de Derechos Humanos de 10 de diciembre de 1948 que dice que «Nadie será objeto de injerencias arbitrarias en su vida privada, su familia, su domicilio o su correspondencia, ni de ataques a su honra o a su reputación. Toda persona tiene derecho a la protección de la ley contra tales injerencias o ataques». En segundo lugar se encuentra también en el artículo 17 del Pacto Internacional de Derechos Civiles y Políticos, hecho en Nueva York el 19 de diciembre de 1966 que establece que: «1.Nadie será objeto de injerencias arbitrarias o ilegales en su vida privada, su familia, su domicilio o su correspondencia, ni de ataques ilegales a su honra y reputación. 2.Toda persona tiene derecho a la protección de la ley contra esas injerencias o esos ataques». Finalmente a nivel europeo es conveniente destacar el artículo 8 del Convenio Europeo para la protección de los Derechos Humanos y de las libertades fundamentales, firmado en Roma el 4 de noviembre de 1950 cuyo tenor literal es: «1.Toda persona tiene derecho al respeto de su vida privada y familiar, de su domicilio y de su correspondencia. 2. No podrá haber injerencia de la autoridad pública en el ejercicio de este derecho, sino en tanto en cuanto esta injerencia esté prevista por la ley y constituya una medida que, en una sociedad democrática, sea necesaria para la seguridad nacional, la seguridad pública, el bienestar económico del país, la defensa del orden y la prevención del delito, la protección de la salud o de la moral, o la protección de los derechos y las libertades de los demás».

Luego, ¿qué se entiende por el derecho al secreto de las comunicaciones?

Lo primero que es necesario aclarar es que este derecho pretende garantizar que todo tipo de comunicación sea protegida, o lo que es lo mismo, que 
nadie ajeno a los interlocutores pueda involucrarse en la conversación si así no lo desean los intervinientes en el proceso comunicativo. Del Texto Constitucional se extrae que aquello que se va a comunicar va a ser secreto, siendo esto una presunción iuris et de iure ${ }^{1}$.

Por este motivo es por lo que se ha considerado que se está ante un derecho formal ${ }^{2}$, que protege el proceso de comunicación, con independencia del contenido del mensaje que se transmita en ese proceso. En ocasiones se ha afirmado que el derecho al secreto de las comunicaciones era equivalente al derecho a la intimidad, pero es precisamente este carácter de derecho formal el que los diferencia, debido a que el derecho a la intimidad es un derecho material en el que sí se va a tener en cuenta la característica de íntimo de aquello que se protege. Por ello, debido a que protegen cosas diferentes, tenemos que decir que se trata de derechos diferentes, y que por lo tanto, el Derecho al secreto de las comunicaciones es un Derecho autónomo ${ }^{3}$.

\section{TITULARES DEL DERECHO AL SECRETO DE LAS COMUNICACIONES}

Si bien es cierto que existen derechos que provocan ciertas dificultades a la hora de determinar quién puede ser titular de los mismos, en el caso del artículo 18.3 de la Constitución, éste hace un enunciado en tercera persona que ya de partida lleva a pensar que la titularidad de los mismos es absoluta, o dicho en otras palabras, que se va a garantizar el secreto de las comunicaciones de todas las personas, incluyéndose aquí tanto a las físicas como a las jurídicas, nacionales y extranjeras. Esto no pudo sino ser confirmado por la jurisprudencia, tanto nacional como comunitaria, y así el Tribunal Constitucional ha incluido sin ningún tipo de duda a las personas extranjeras dentro de la protección de este derecho ${ }^{4}$, y tanto el Tribunal Europeo de Derechos

1 Rebollo Delgado, L., «El secreto de las comunicaciones: problemas actuales», Revista de Derecho Politico, núm. 48-49, 2000, p. 363.

2 Así se ha pronunciado el Tribunal Constitucional en sus Sentencias 114/1984, de 29 de noviembre, FJ 7, 34/1996, de 11 de marzo FJ4 y 70/2002, de 3 de abril, FJ 9.

3 Rodríguez Ruíz, B., El secreto de las comunicaciones: tecnología e intimidad, McGraw HiJi, Madrid, 1998, p. 1.

${ }^{4}$ STC 236/2007, de 7 de noviembre, FJ 3. En esta Sentencia el Tribunal Constitucional determina que existen derechos que deben extenderse a los extranjeros por estar íntimamente vinculados con la dignidad de la persona. También se ha manifestado en este sentido la doctrina más relevante como DíAz REVORIDO, quien concretamente dice que «en el caso del secreto de las comunicaciones, tratándose de un derecho de la esfera privada, vinculado directamente a la dignidad humana, la titularidad debe recaer en toda persona, con independencia de su nacionalidad, y por lo tanto no cabe establecer excepciones, privaciones o limitaciones específicas para el caso de los extranjeros». DíAz RE- 
Humanos como el Tribunal de Justicia de las Comunidades Europeas se han encargado de hacer lo propio con las personas jurídicas ${ }^{5}$, de tal manera que la primera idea de considerar que este derecho cuenta con una titularidad absoluta queda más que confirmado por los Tribunales.

\section{PROBLEMAS A LA HORA DE INTERVENIR LAS COMUNICACIONES}

Una cuestión fundamental a nivel práctico en relación con la intervención de las comunicaciones, reside en que es frecuente que en el momento de intervenirlas aparezcan distintos inconvenientes, los cuales pasaremos a analizar a continuación observando sus correspondientes soluciones. No obstante, como paso previo al análisis de estos inconvenientes, resulta imperativo saber que se entiende por intervención de las comunicaciones, y de ello, el Tribunal Supremo ha ofrecido de forma reiterada una definición bastante clara de las intervenciones telefónicas que se puede aplicar para la generalidad de las intervenciones, de tal manera que las intervenciones cuentan con varias características, entre ellas se puede observar que se las trata de una medida instrumental, ordenada por la autoridad judicial y que va a tener una finalidad investigadora y para obtener medios de prueba. Literalmente el Tribunal Supremo señaló que se trata de «unas medidas instrumentales que suponen una restricción del derecho fundamental del secreto de las comunicaciones y que aparecen ordenadas por el Juez de Instrucción en la fase instructora o sumarial del procedimiento penal, bien frente al imputado, bien frente a otros con los cuales éste se comunique, con la finalidad de captar el contenido de las conversaciones para la investigación de concretos delitos y para la aportación en su caso, de determinados elementos probatorios $»^{6}$.

\section{VULNERACIÓN DE UN DERECHO FUNDAMENTAL}

Así, en primer lugar nos encontramos con un obstáculo genérico que puede aplicarse a todos los mecanismos que sirven para la obtención de pruebas. Éste

VORIDO, F. J., «El derecho fundamental al secreto de las comunicaciones», Derecho PUCP: Revista de la Facultad de Derecho, núm. 59, 2006, p. 161.

${ }_{5}$ STEDH de 16 de febrero de 2000, caso Amann contra Suiza y STJCE de 18 de mayo de 1982, asunto 155/79, AM \& S Europe Limited contra Comisión de las Comunidades Europeas (ECLI:EU:C:1982:157).

${ }^{6}$ STS 2093/1994, de 28 de noviembre FJ 7 (RJ 1994\9997), 246/1995, de 20 de febrero, FJ 8 (RJ 1995\1201), 711/1996, de 19 de octubre, FJ 1 (RJ 1996\7834), 740/1997 de 26 mayo. RJ FJ1, (1997\4133)579/1998 de 22 abril, FJ 2, (RJ 1998\3811), o 21 de noviembre de 1999 y el Auto 325/2001 de 21 febrero FJ Único, (RJ 2001\6140). 
es el respeto absoluto a los derechos fundamentales consagrados en la Carta Magna. En este sentido se encuentra el artículo 11.1 de la Ley Orgánica del Poder Judicial cuando dice que «no surtirán efecto las pruebas obtenidas, directa o indirectamente, violentando los derechos o libertades fundamentales».

En el caso de la intervención de las comunicaciones, ¿cómo se garantiza que no se vulnera el derecho al secreto de las comunicaciones?. La respuesta a esta cuestión era sencilla hasta el año 2015. En primer lugar se entendía que este derecho fundamental se vulneraba cuando la intervención se realiza sin una base judicial, o lo que es lo mismo, sin autorización del juez, debido a que el propio precepto constitucional que protege las comunicaciones habla de la resolución judicial como excepción a la protección ${ }^{7}$. No obstante, con la reforma que se ha realizado de la Ley de Enjuiciamiento Criminal, y que ya ha entrado en vigor, nos encontramos con una modificación del artículo 579 , precepto que regula la intervención de las comunicaciones, y es que en la reforma que se ha llevado a cabo se establece una excepción que, con la Constitución Española en la mano, presenta una importante duda acerca de su constitucionalidad. El apartado cuarto del precepto reza del siguiente modo: «En caso de urgencia, cuando las investigaciones se realicen para la averiguación de delitos relacionados con la actuación de bandas armadas o elementos terroristas o rebeldes, la medida prevista en el número 3 de este artículo podrá ordenarla el Ministro del Interior o, en su defecto, el Director de la Seguridad del Estado, comunicándolo inmediatamente por escrito motivado al Juez competente, quien, también de forma motivada, revocará o confirmará tal resolución en un plazo máximo de setenta y dos horas desde que fue ordenada la observación». Esto sin duda no es nuevo en países de nuestro entorno jurídico, ya que mismamente en Italia también aparece una regulación similar ${ }^{8}$, pero ello no obsta para que se estén saltando lo dispuesto

${ }^{7}$ A este respecto cabe señalar que el propio Tribunal Constitucional se ha expresado e incluido dentro de las garantías constitucionales del derecho al secreto de las comunicaciones la autorización judicial con una motivación suficiente, así entre otras cabe citar la SSTC 166/1999, 27 de septiembre, FJ 2; 299/2000, de 11 de diciembre, FJ 2; 14/2001, de 29 de enero, FJ 2 y la STC 70/2002, de 3 de abril, FJ 9.

${ }^{8}$ En Italia, un país con el que España comparte múltiples similitudes jurídicas, se ha establecido una excepción en lo referente a la autorización judicial, si bien es cierto que la Constitución Italiana, en su artículo 15, proclama el derecho al secreto de las comunicaciones de la siguiente manera «La libertà e la segretezza della corrispondenza e di ogni altra forma di comunicazione sono inviolabili. La loro limitazione può avvenire soltanto per atto motivato dell'autorità giudiziaria con le garanzie stabilite dalla Ley»y. A tenor de este precepto observamos que a simple vista las comunicaciones solo se podrán limitar en base a una motivación por parte de la autoridad judicial, sin embargo, el Código Procesal Penal Italiano ha establecido una excepción señalando en su artículo 267.2 que en los casos en los que se tenga la creencia de que si se espera por la autorización judicial, esto perjudicaría la investigación, 
en el precepto constitucional, el cual, atendiendo a su tenor literal, no ofrece opción acerca de quién debe autorizar la intervención. Evidentemente en caso de que el Juez competente convalide la medida tomada por el Ministerio Público, esto no supondría demasiados problemas, ya que aunque se sigue saltando lo dictaminado por el Constituyente español, se produciría una especie de arreglo posterior, no por ello justificable, pero dentro del mal producido sería una situación que podría ser tolerada, sin embargo, el problema más grave se produciría en aquella situación en la cual el juez considera que la medida no debe ser llevada a cabo, la vulneración del derecho ya se habría producido con independencia de que, como no podía ser de otro modo, los datos obtenidos en la intervención no puedan ser utilizados. En los casos en los cuales la autoridad judicial encargada del caso no estuviese disponible para autorizar la medida en ese momento, sería más acertado que se pudiese acudir a otra autoridad judicial aunque sea ajena al asunto, así por ejemplo en España, el Tribunal Constitucional ha admitido que la intervención sea autorizada por un juez diferente al que lleva la instrucción ${ }^{9}$. Hay que tener presente que el respeto de los derechos fundamentales ha de ser siempre máximo, no pudiéndose saltar las reglas establecidas en la Constitución por el afán de averiguar un hipotético hecho delictivo ${ }^{10}$.

Además de esta vulneración que acaba de mencionarse, y retomando con las situaciones en las que se produciría una vulneración del derecho a la inviolabilidad de las comunicaciones, también supone una vulneración del derecho la falta de motivación en el auto del juez que permite la intervención ${ }^{11}$,

la intervención podrá ser autorizada por el Ministerio Público, siendo esta decisión trasladada al juez que esté encargado de las investigaciones preliminares en un plazo máximo de 24 horas, y debiendo pronunciarse el juez dentro de las 48 horas siguientes en relación a si apoya la medida del Ministerio o no. Sin embargo, al igual que en la actual versión de la Ley de Enjuiciamiento Criminal española, este precepto del ordenamiento italiano podría adolecer de un vicio de inconstitucionalidad, ya que parece que la Constitución Italiana no deja margen para que sea alguien distinto a la autoridad judicial el que autorice la intervención. Se podría pensar que el inciso que hace el precepto constitucional italiano remitiéndose a la Ley, sería suficiente para que sea una persona distinta a la autoridad judicial la que autorice la intervención siempre que la Ley mantenga la convalidación de la medida por parte de dicha autoridad, pero esta interpretación sería en exceso extremista.

9 STC 126/2000 de 16 de mayo, FJ 5.

${ }^{10}$ En este sentido también se ha pronunciado Ariel Ramírez al afirmar que «la averiguación de cualquier hecho delictivo no puede llevarse a cabo a cualquier precio, y menos vulnerando los derechos fundamentales reconocidos por la Constitución y el Estado democrático». RAMíREZ MARTíNEZ, A., Las intervenciones telefónicas en el derecho penal boliviano, Ariel Ramírez Martínez, Cochabamba, 2014, p. 35.

${ }_{11}$ El Tribunal Constitucional ha afirmado en relación con esto, que la motivación de indicios debe ir más allá de las meras suposiciones o conjeturas. Por todas, la STC 49/1999, de 5 de abril, FJ 8 y STC 219/2009, de 21 de diciembre, FJ 4. 
la falta de control judicial desde el inicio hasta el fin de la intervención, no pudiendo faltar en ningún momento, la indeterminación temporal de la intervención, la falta de especificación del objeto principal de la misma o el incumplimiento del principio de proporcionalidad ${ }^{12}$.

Ahora bien, unido a esto está la posibilidad de afectar al derecho a la inviolabilidad de las comunicaciones de otras personas. Esta situación se produce con una gran facilidad, y es que debe tenerse en cuenta que cuando se autoriza judicialmente la intervención de las comunicaciones, generalmente ésta es autorizada respecto de una persona concreta y determinada, pero esta persona se va a comunicar con otras, ya que el propio significado del proceso comunicativo así lo exige. Teniendo esto en cuenta, el problema se encuentra en que las personas que se comunican con el sujeto que tiene intervenidas sus comunicaciones, ven una intromisión en su derecho, intromisión que respecto de ellos nadie ha autorizado.

Hay que recordar, que una intervención de la comunicación no se va a ceñir únicamente a lo dicho por una persona, sino que habrá que mirar las comunicaciones en conjunto, en un sentido amplio ${ }^{13}$. Este sentido amplio implica que la intromisión que no ha sido autorizada a la que se hacía referencia hace unos instantes es sencillamente necesaria. La clave está en conocer qué consecuencias tiene esta intromisión, si es que las tiene.

Acudiendo a las normas procesales, la Ley de Enjuiciamiento Criminal, en su artículo 579, a pesar de su reciente modificación, no ofrece ningún tipo de solución ni aclaración al respecto, por lo que la legislación vigente no va a servirnos de punto de apoyo para saber que sucede con el asunto, siendo imperativo acudir a la jurisprudencia. A este respecto, el Tribunal Supremo ${ }^{14}$ se ha pronunciado ante una situación como la que se ha descrito, señalando que las pruebas que se hayan obtenido en relación con la intervención, pueden considerarse como prueba de cargo sin que sea considerada una prueba ilícita, siempre que esté referida al objeto delictivo que se investiga y por el cual se ha solicitado la intervención de la comunicación. El razonamiento del Tribunal es completamente lógico y acertado, debido a que si se cumplen los requisitos legales establecidos para llevar a cabo la intervención, ésta se realiza con la finalidad de conocer detalles de la investigación que esté en curso,

12 Noya Ferreiro, L., «Presupuestos constitucionales de las medidas de intervención de las comunicaciones I», Dereito. Revista xuridica da Universidade de Santiago de Compostela, vol. 8, núm. 2, pp. 145-166. Circular 1/2013 de la Fiscalía General del Estado, de 11 de enero, sobre pautas en relación con la diligencia de intervención de las comunicaciones telefónicas, p. 115.

${ }^{13}$ Rodríguez Lainz, J. L., y Marchena Gómez, M., Estudios sobre el secreto de las comunicaciones. Perspectiva doctrinal y jurisprudencial, La Ley, Madrid, 2011, p. 126.

${ }^{14}$ STS 433/2012, de 1 de junio FJ 19 (RJ 2012\6722). 
por lo que carecería de sentido tener que identificar a todos los participantes en el acto comunicativo, los cuales muchas veces van a ser desconocidos.

Por su parte, el Tribunal Constitucional ha llegado a una conclusión similar a la del Tribunal Supremo, estableciendo la teoría de los «usuarios habituales» ${ }^{15}$. De esta manera, cuando se autoriza una intervención de las comunicaciones, todas las personas que mantienen comunicación asidua con la persona sobre la que se ha autorizado la intervención, se encontrarían implícitamente incluidos en la autorización judicial.

Hay que tener presente que si en la intervención de las comunicaciones se descubre la implicación de terceras personas en la comisión de los hechos delictivos que se están investigando, se va a requerir una ampliación del auto primero dictado por el juez para intervenir las comunicaciones, mientras que en caso de que se tratase de delitos nuevos, se requeriría una autorización nueva sin servir de nada una ampliación ${ }^{16}$.

Llegados a este punto, hay que aclarar que dentro de estas posibilidades de vulnerar el derecho fundamental al secreto de las comunicaciones está la situación en la cual uno de los interlocutores graba la conversación, lo cual merece una mención aparte. En este supuesto ¿existe verdaderamente una vulneración del derecho al secreto de las comunicaciones?. Llegados a este punto es conveniente analizar la finalidad del derecho. El derecho al secreto de las comunicaciones nace con la finalidad de proteger el acto comunicativo de terceras personas ajenas al mismo, por lo tanto, no se pretende proteger la comunicación para los propios comunicantes, pues esto resultaría ilógico. Dada esta finalidad, se puede decir que si uno de los participantes en el acto comunicativo decide grabar la conversación, aunque esta grabación se produzca sin conocimiento del resto de comunicantes, no se vulnera el derecho al secreto de las comunicaciones. Empero hay que tener cuidado, ya que sí es posible que, en el caso de que esa grabación se utilice, se puedan vulnerar otros derechos como por ejemplo el derecho a la intimidad, dependiendo del contenido del mensaje, $\mathrm{u}$ otros distintos. Claramente dice el profesor Fernández Rodríguez que entre las personas que ocupan el papel de emisor y de receptor no existe la obligación de secreto ${ }^{17}$. También el Alto Tribunal se ha pronunciado a este respecto entendiendo lo expuesto, y así queda constatado en su Sentencia 114/1984, de 29 de noviembre ${ }^{18}$.

15 STC 184/2003, de 23 de octubre, FJ 4.

16 LóPeZ-Barajas Perea, I., La intervención de las comunicaciones electrónicas, La Ley, Madrid, 2011, p. 167.

${ }_{17}$ Fernández Rodríguez, J. J., Secreto e intervención de las comunicaciones en internet, Thomson Civitas, Madrid, 2004, p. 109.

${ }^{18}$ STC 114/1984, de 29 de noviembre, FJ 7. 
Una importante cuestión que debe tratarse también es la relativa a que sucede con la culpabilidad del propio investigado de la que se tiene conocimiento mediante la intervención de las comunicaciones, pero esta intervención deviene nula por no haber respetado el contenido esencial del derecho fundamental del derecho al secreto de las comunicaciones. Aquí deben distinguirse dos posibles situaciones, la primera de ellas, es aquella en la que en el proceso comunicativo que se interviene existe una declaración propia de culpabilidad. La segunda situación es aquella en la cual a partir de conocer esa intervención, la persona en cuestión decide declararse culpable siendo posteriormente anulada la intervención.

En el primero de los casos, no hay duda, ante la falta de efectos de la intervención, también quedaría sin efectos dicha autoinculpación, y más específicamente, aun en el caso de que no se produzca la nulidad de la intervención, un importante sector doctrinal considera que no se debe entender como prueba esa autoinculpación, a causa de que no se está prestando declaración strictu sensu $u^{19}$, es más, se ha afirmado que «la fuente de prueba obtenida con una medida de intervención telefónica nunca podrá tener como contenido una confesión o un testimonio del imputado o de otros sujetos pasivos de la medida ${ }^{20}$, y es que es necesario recordar que la Constitución Española de 1978 consagra en su articulado el derecho a no declarar contra uno mismo, recogido como parte del derecho fundamental a la tutela judicial efectiva del artículo 24 del Texto Constitucional.

En el segundo de los casos debe aclararse que la jurisprudencia no ha llegado a un acuerdo unánime sobre el tema, así, el Tribunal Supremo ${ }^{21}$, establece de forma acertada, que si la declaración de culpabilidad se ha realizado respetando las garantías exigibles a ella, será igualmente válida a pesar de que la intervención no lo sea. Estas garantías son las de información de los derechos, inmediación, oralidad y contradicción. En un sentido similar se ha pronunciado la Fiscalía General del Estado, que ha establecido que para que la autoinculpación sea considerada válida en este supuesto será necesario que se informe a la persona imputada acerca de sus derechos, especialmente el derecho a no declararse culpable y a no declarar contra sí mismo, realizándose ante el juez, y requiriéndose la asistencia de letrado y la falta de vicios en la declaración, siendo ésta libre y voluntaria ${ }^{22}$.

${ }_{19}$ Entre otros, Martín Morales, R., El régimen constitucional del secreto de las comunicaciones, Civitas, Madrid, 1995, p. 105.

${ }^{20}$ López-Fragoso Álvarez, T., Las intervenciones telefónicas en el proceso penal, Cólex, Madrid, 1991, p. 117.

${ }_{21}$ STS 768/2010, de 15 de septiembre, FJ 10. (RJ 2010\7823).

22 Circular 1/2013 de la Fiscalía General del Estado, de 11 de enero, sobre pautas en relación con la diligencia de intervención de las comunicaciones telefónicas. 


\subsection{Secreto de las actuaciones en el proceso penal}

El derecho penal es conocido como la última ratio, reservándose para los comportamientos más reprochables. Hay que tener presente que en España, la intervención de las comunicaciones únicamente va a poder realizarse en el marco de un proceso penal. Sin embargo esto no lo establece la Constitución propiamente dicho, sino que ha sido fruto de la jurisprudencia, así el Tribunal Constitucional ha considerado que la habilitación de la intervención se encuentra en «la existencia de una investigación en curso por un hecho constitutivo de infracción punible grave, en atención al bien jurídico protegido y a la relevancia social del mismo $»^{23}$. No obstante, el mismo Tribunal ha realizado una aclaración ante esto señalando que no se produce una vulneración del artículo 18.3 si se produce en las diligencias indeterminadas ${ }^{24}$, dirección que comparte a su vez el Tribunal Supremo ${ }^{25}$, el cual también se ha manifestado en este sentido diciendo que «con relación al tema de las Diligencias Indeterminadas, debemos proclamar que el decreto de intervención acordado en tal procedimiento no determina nulidad alguna (ver, por todas, las sentencias de esta Sala de casación 768/1995, de 14 de junio, 20/1996, de 28 de marzo y 438/1996, de 24 de junio), pues como dice al respecto la 273/1997, de 24 de febrero, si bien hubiera resultado más correcto y ortodoxo dictar el auto cuestionado en diligencias previas al no estar previstas especificamente en nuestra legislación las Indeterminadas, ello no supone en modo alguno defecto invalidante, ya que cualquier infracción procesal no implica "per se" la vulneración del art. 24 CE porque el elemento habilitante de la restricción, según el referido Texto Fundamental, se encuentra, no en el procedimiento donde se dicta sino en la resolución judicial que la acuerda. Basta por ello con el auto del juez con la fe del Secretario, sin que tenga que ver el que en tal etapa procesal y el especifico procedimiento se califique de Previas o Indeterminadas». Esto ha sido criticado con acierto por un sector doctrinal que consideran incorrecto la autorización de una intervención en estas diligencias ${ }^{26}$.

${ }^{23}$ STC 166/1999 de 22 de febrero.

${ }^{24}$ STC 49/1999 de 5 de abril, 126/2000 de 16 de mayo, 165/2005 de 20 de junio y 259/2005 de 24 de octubre.

${ }_{25}$ STS 320/1998, de 7 de marzo de 1998. FJ 2. (RJ 1998\2345).

${ }^{26}$ Un ejemplo de ello sería DE LLERA, el cual considera que debe autorizarse cuando el proceso penal está abierto, siendo lo contrario una práctica ilegal y viciosa por parte del órgano judicial, también en este sentido se ha pronunciado López Barja de Quiroga, quien dice más contundentemente que es imprescindible que esté abierta una causa penal para poder acordarse las intervenciones. De LleRA SuÁREZ-BÁRCENA, E., «El régimen jurídico ordinario de las observaciones telefónicas en el proceso penal», Poder Judicial, núm. 3, pp. 18-19, y LÓPEZ BARJA DE QUIROGA, J., Las escuchas telefónicas y la prueba ilegalmente obtenida, Akal Iure, Madrid, 1989, p. 185. 
Además en España, el proceso penal es un proceso contradictorio, que presenta múltiples garantías. Entre el entramado de garantías presentes en el proceso penal, se regula en el artículo 118 de la Ley de Enjuiciamiento Criminal la obligación de poner en conocimiento de la persona que se ve inmerso en un proceso penal, las actuaciones que requieran su comparecencia. Así, a simple vista, este precepto parece establecer una obligación de alertar a la persona en el caso de que se intervengan sus comunicaciones, pero esto no es así, ya que de ponerlo sobre aviso, la intervención perdería su sentido de ser. Es por ello que la intervención de las comunicaciones va a ser una actuación que gozará de una cualidad importante, siendo ésta que será una actuación secreta para el investigado.

Ahora bien, no con esto se soluciona el problema. Si confrontamos los artículos 579 y 302 de la Ley de Enjuiciamiento Criminal, nos vamos a encontrar con un silencio por parte del primero de los preceptos, regulador de las intervenciones, y una necesidad de que las partes tengan conocimiento de los actos practicados en el proceso salvo decisión contraria del órgano judicial, que ordena el segundo, por lo que cabe preguntarse ¿en el caso de una intervención de las comunicaciones, el secreto opera de forma inmediata o es necesario que sea decretado su secreto por parte de un juez tal y como ordena el artículo 302 ? El Tribunal Supremo se ha pronunciado a este respecto, señalando que sí será necesario solicitar junto con la autorización de la intervención, su secreto ${ }^{27}$. No obstante, sigue diciendo el Tribunal, que en el caso en el cual no se solicite este secreto, ello sería considerado como una irregularidad sin suponer la nulidad de las actuaciones. Por ello, tanto si se solicita el secreto como si no, las actuaciones conservan plena validez, así como lo que se descubra con ellas. Sin embargo, y entendiendo la decisión del Tribunal, quien intenta acercarse a la postura del artículo 302, la realidad es que se procura es salvaguardar el contenido de la intervención, por lo que lo ideal sería que en la intervención de las comunicaciones, el secreto se produjese de forma automática, siendo recomendable que en una futura revisión de la norma procesal, se regulase de esta forma. Revisión que también se requiere para solucionar el problema que se produce una vez se acuerda la intervención y el secreto, y es que en atención a la Ley, el plazo máximo por el que se decretará el secreto de sumario será de 1 mes, pero el plazo para la intervención de las comunicaciones es de 3 meses, siendo incluso posible solicitar una prórroga del mismo. Por lo tanto se puede observar claramente el evidente conflicto entre ambos plazos, conflicto que se resuelve permitiendo la prórroga del plazo de un mes para el secreto.

Ahora bien, hay quien se ha planteado si el ampliar el plazo del secreto de sumario supondría una situación de indefensión respecto de la persona

${ }^{27}$ STS 742/2002, de 24 de abril, FJ 3 (RJ 2002\7338). 
que sufre esta ampliación. En relación con esto, el Tribunal Constitucional $^{28}$ se ha pronunciado negando que simplemente con una prórroga del secreto de sumario se cause una situación de indefensión, debiendo examinarse si es imputable dicha prórroga a un retraso malicioso por parte de la Administración de Justicia. Lo dicho por el Alto Tribunal español es completamente acertado, y es que hay que tener en cuenta que la norma procesal no prohíbe una ampliación del plazo, sino que simplemente no lo menciona, por lo que plantear una prórroga no va a suponer una contradicción de ningún precepto procesal, siendo incluso necesario en algunos casos para un mejor esclarecimiento de los hechos, consiguiendo así un proceso más justo y garantista.

Sabiendo esto, en el caso que nos ocupa de intervención de las comunicaciones, se puede afirmar que esta prórroga del plazo se puede llevar a cabo, pero no debe convertirse en la regla general, sino en la excepción, procediendo únicamente cuando sea necesaria y debiendo motivarla.

\subsection{Descubrimientos ocasionales}

Finalmente, el último obstáculo a tener en cuenta es el relativo a los llamados descubrimientos ocasionales o casuales ${ }^{29}$. Cuando se habla de estos descubrimientos, se hace referencia a información no conocida hasta ese momento que puede afectar tanto a la persona investigada como a terceras personas ${ }^{30}$. Hay que advertir que esta información nueva puede guardar una relación con el delito investigado o bien ser ajena a éste.

La autorización judicial de la intervención de las comunicaciones se hace de forma muy específica, concretando bien el motivo por el cual se concede la autorización, sabiendo el delito, hechos o actividades que se investigan. $A$ priori cabe señalar que aquellos hechos ajenos deberían ser prescindibles de la intervención, o lo que es lo mismo, no tomarse en consideración, y en este sentido existe un sector doctrinal que considera que la falta de cobertura legal existente en relación con estos descubrimientos deberían suponer su nuli-

${ }^{28}$ STC 176/1988, de 4 de octubre, FJ 4. Posteriormente el Tribunal Supremo ha compartido el criterio del Alto Tribunal, ejemplo de lo cual son el ATS 756/1996, de 12 de mayo, FJ 2 (RJ 1999\4976), la STS 510/2005, de 22 de abril, FJ 5 (RJ 2005\4315), STS 1601/2005, de 22 de diciembre, FJ6 (RJ 2006\593), STS 165/2013, de 26 de marzo, FJ 23 (RJ 2013\6412), STS 559/2014, de 8 de julio, FJ 2 (RJ 2014\4025).

${ }^{29}$ Un estudio realmente interesante al respecto es: Álvarez DE NEYRA Kappler, S., «Los descubrimientos casuales en el marco de una investigación penal (Con especial referencia a las diligencias de entrada y registro en domicilio)», Revista Internacional de Estudios de Derecho Procesal y Arbitraje, núm. 2, 2011.

${ }^{30}$ Alonso PÉrez, F., Intervención de las comunicaciones postales, telegráficas y telefónicas, Dykinson, Madrid, 2001, p. 123. 
$\mathrm{dad}^{31}$, careciendo por tanto de efectos jurídicos. Pues bien, aunque esta postura es admisible, si estos nuevos hechos son ilícitos no sería ideal optar por la pasividad ante ellos, por lo que quizá sería más acertado considerar que «los descubrimientos casuales únicamente podrán servir para fundar una sospecha necesaria para incoar un sumario o unas diligencias previas, pero no para fundamentar, por sí solos, no ya la posible condena, sino tampoco la imputación» ${ }^{32}$.

Una vez dicho esto, vamos a determinar que se debe hacer ante esta situación. Como en el caso del obstáculo anterior, debemos acudir primero a la legislación española, la cual veremos que no se ocupa de resolver éste problema tan concreto y perfectamente plausible, cosa que sí puede observarse en el derecho comparado, como en la Ordenanza Procesal alemana en su artículo $100 \mathrm{~b}$ ) que establece la posibilidad de usar la información casual si estuviese referida a actividades delictivas que supondrían, en su caso, una autorización judicial para intervenir las comunicaciones.

Lo que sí existe en España es la conocida Circular 1/2013 de la Fiscalía General del Estado, de 11 de enero, sobre pautas en relación con la diligencia de intervención de las comunicaciones telefónicas. En esta circular se dice que en el caso en el cual se descubran hechos relacionados con el principal, se deberá solicitar al juez una orden ampliatoria de la primera para que no se produzca una vulneración. Aunque esta circular no supone ningún tipo de vínculo a los jueces, en este punto ha sido seguida por el Tribunal Supremo ${ }^{33}$, quedando resuelta así esta situación.

Ahora bien, para el caso en el que se trate de nuevos descubrimientos que no guarden relación con el objeto que incentivó la intervención primera, se va a precisar un nuevo auto que autorice la intervención, pero será imprescindible que se cumplan dos requisitos. El primero es que el juez sea competente para conocer de los nuevos hechos que se han descubierto, y el segundo, que el juez compruebe que se cumple el principio de proporcionalidad ${ }^{34}$. De tal manera que el hecho casual de un acto delictivo ajeno a la investigación principal permite que se pueda investigar la nueva situación de la que se tiene constancia.

\subsection{Secreto entre abogado y cliente}

Más que un problema propiamente dicho, una situación que resulta muy interesante tratar es aquella que guarda relación con el secreto profesional,

${ }_{31}$ Paz RuBIO, J. M., «La prueba en el proceso penal», Cuadernos de derecho Judicial, 1992.

32 López-Fragoso Álvarez, T., Las intervenciones telefónicas en el proceso penal, Colex, Madrid, 1999, p. 92.

${ }_{33}$ STS 551/2013, de 18 de junio, FJ 1 (RJ 2013\8318).

34 SuÁrez Robledano, J. M., «Intervención de comunicaciones electrónicas», Foro: Revista de ciencias jurídicas y sociales, núm. 14, 2011, pp. 73-99. 
siendo una situación que puede generar dudas y conflicto sobre cómo proceder.

Existe un criterio prácticamente unánime en considerar que la Administración dentro de sus competencias de investigación, va a verse limitada por el derecho a la legítima defensa, este derecho, para que este derecho pueda encontrar su mayor eficacia va a exigir tanto un secreto profesional del abogado en relación con la documentación de su cliente, y como el secreto de las comunicaciones entre el cliente y el abogado ${ }^{35}$ propiamente dichas. Esto que a simple vista puede parecer algo lógico, es además una exigencia establecida en el Código Deontológico de la Abogacía Española ${ }^{36}$, también se establece la obligación de realizar una defensa con libertad e independencia con un respeto pleno a su función ${ }^{37}$, todo ello con el establecimiento del deber de diligencia profesional ${ }^{38}$. Dentro de estas obligaciones se puede intuir claramente la existencia de un derecho al secreto de las comunicaciones entre el abogado y el cliente. La existencia de este derecho se ve reforzado gracias a la Ley de Enjuiciamiento Criminal, la cual en su artículo 263 excusa a los abogados y procuradores de cumplir la obligación de denunciar el delito público del que tuviesen noticia por razón de su cargo, profesión u oficio impuesta por el artículo 262 párrafo primero. A su vez, el 416.2 de la misma norma excusa directamente al abogado de declarar, estableciendo de forma literal que «Están dispensos de la obligación de declarar: El Abogado del procesado respecto a los hechos que éste le hubiese confiado en su calidad de defensor $\rangle^{39}$. Finalmente, el artículo 542.3 LOPJ establece una obligación de secreto aplicable a todos los abogados en relación con los hechos o noticias de las que tuviesen conocimiento por razón de su cargo, y a su vez, refuerza el precepto la no obligación de declarar sobre esos hechos o noticias.

Por todo ello puede decirse que a priori, las comunicaciones entre el abogado y su cliente no van a poder ser intervenidas con carácter general, pero como toda regla general existen excepciones, así, la Ley Orgánica 1/1979, de

35 FERNÁndez LóPEZ, J. M., «Las inspecciones de las autoridades de la defensa de la competencia y los derechos de los inspeccionados», en: CASES, L. (Dir.), Anuario de la Competencia, Servei de Publicacions de la Universitat Autònoma de Barcelona, Bellaterra, 2010, p. 149.

36 Artículo 5.

37 Artículos 2 y 3 CDAE y art. 33 EGAE.

${ }_{38}$ Artículos 32.1 y 42 del RD 658/2001, de 22 de junio, por el que se aprueba el Estatuto General de la Abogacía Española.

39 Dicho precepto encuentra un refuerzo en el artículo 707 que establece que«Todos los testigos que no se hallen privados del uso de su razón están obligados a declarar lo que supieren sobre lo que les fuere preguntado, con excepción de las personas expresadas en los artículos 416, 417 y 418, en sus respectivos casos». Excluyéndose por tanto a los abogados en su caso. 
26 de septiembre, General Penitenciaria, se refiere a este derecho en el apartado segundo del artículo 51 diciendo que «Las comunicaciones de los internos con el Abogado defensor o con el Abogado expresamente llamado en relación con asuntos penales y con los Procuradores que los representen, se celebrarán en departamentos apropiados y no podrán ser suspendidas o intervenidas salvo por orden de la autoridad judicial y en los supuestos de terrorismo».

Si bien este precepto es bastante claro y conciso en cuanto a las personas entre las que la comunicación se interviene. Sin embargo, se han planteado dudas acerca de si la última parte dónde se señala que se va a requerir la orden de la autoridad judicial y en los supuestos de terrorismo, se trataban de dos aspectos alternativos o acumulativos. En relación con esto se ha pronunciado, como no podía ser de otra forma, el Tribunal Constitucional diciendo que «la imposibilidad constitucional de interpretar este último precepto en el sentido de considerar alternativas las dos condiciones de orden de la autoridad judicial (...) y supuestos de terrorismo que en el mismo se contienen (...) dichas condiciones habilitantes deben, por el contrario, considerarse acumulativas ${ }^{40}$, más tarde el Alto Tribunal reafirmaría su criterio con más contundencia «debían ser interpretados como acumulativos y no como alternativos $\rangle^{41}$. El Tribunal Supremo también ha aplicado el criterio marcado por el Constitucional en distintas sentencias como 6 de marzo de $1995^{42}$ o la de 23 de abril de $1997^{43}$, la interpretación del mismo debe ser restrictiva, y la autoridad judicial deberá actuar de la forma más cautelosa posible a la hora de autorizar dicha intervención.

Por su parte la jurisprudencia no se ha silenciado al respecto ni ha adoptado una posición ambigua, así la STJCE de 18 de mayo de $1982^{44}$ estableció de forma clara que existía un derecho a que la correspondencia entre un abogado y su cliente fuese secreto. Hay que tener en cuenta que el Tribunal Europeo de Derechos Humanos ha señalado de una forma totalmente correcta que sería realmente complicado que un inculpado en un asunto pueda ser asistido de forma adecuada por su abogado si no disponen de un contacto previo entre ellos que sea reservado, o lo que es lo mismo protegido de intervenciones ${ }^{45}$. Al mismo tiempo, en la Sentencia del mismo Tribunal de 2 de noviembre de 1991 (S. contra suiza), se establece un derecho por parte del acusado a comunicarse con su abogado sin que esta comunicación llegue a oídos de terceros, en la misma dirección el Tribunal Europeo de Derechos

\footnotetext{
40 STC 183/1994, de 20 de junio, FJ 5.

41 STC 58/1998, de 16 de marzo, FJ 2.

42 STS 245/1995, de 6 de marzo, FJ 1 (RJ 1995\1808).

43 STS 538/1997, de 23 de abril, FJ 7 (RJ 1997\3259).

${ }_{44}$ STJCE de 18 de mayo de 1982, asunto 155/79, AM \& S Europe Limited contra Comisión de las Comunidades Europeas (ECLI:EU:C:1982:157).

${ }^{45}$ STEDH de 28 de junio de 1984 (Campbell y Fell contra Reino Unido).
} 
Humanos consideró que el secreto se va a ver extendido a la entrevista que tengan el abogado y cliente, formando así parte del derecho de defensa, siendo una manifestación del mismo ${ }^{46}$, y es que la STEDH de 1 de octubre de 2009 (Tsonyo Tsoney contra Bulgaria) ha establecido que la correspondencia de un abogado se encuentra en una situación privilegiada con independencia de la finalidad que tenga. Por su parte, en España, el Tribunal Supremo, se ha pronunciado sobre el tema señalando que dentro del derecho de defensa va a ser indispensable el secreto de las comunicaciones entre el abogado y su cliente como principio de confidencialidad ${ }^{47}$.

\section{RECAPITULACIÓN}

En este momento es conveniente hacer una recapitulación de todo lo dicho hasta ahora. En primer lugar, hay que advertir que el fundamento constitucional a la técnica de intervención de las comunicaciones se encuentra en el derecho fundamental al secreto de las comunicaciones consagrado en el artículo 18.3 de la Constitución Española de 1978.

El precepto constitucional marca un requisito mínimo que resulta necesario cumplir para llevar a cabo esta diligencia de intervención, el cual es la imperiosa necesidad de contar con una autorización judicial. Sin embargo, con la última modificación de la Ley de Enjuiciamiento Criminal esto se pone en tela de juicio, a saber cómo va a resolverse, aun con todo, y considerando la nueva normativa, más tarde o más temprano, la autorización judicial hace su presencia, ahora bien, dicha autorización no va a impedir que la intervención se encuentre con problemas relativos a su ejecución. Tres son los problemas básicos que se pueden encontrar, a saber la vulneración de derechos fundamentales, el secreto de la intervención y la utilización de los descubrimientos causales que se obtengan de la intervención.

Estos problemas se han solucionado de forma mayoritaria gracias a la jurisprudencia, siendo necesario que la norma procesal vigente sea actualizada y plasme estas soluciones en su contenido, consiguiendo de esta manera una legislación coherente y adaptada a las situaciones que han ido surgiendo a lo largo de los años.

\section{CONCLUSIÓN}

Antes de la aprobación de la Texto Constitucional actual pueden verse distintos antecedentes en cuanto a la regulación del derecho al secreto de las

46 STEDH de 15 de noviembre de 1996 (caso Domenichini contra Italia), en esta misma dirección encontramos la STEDH de 25 de marzo de 1998 (caso Koop contra Suiza).

${ }^{47}$ STS 79/2012, de 9 de febrero, Fundamento Jurídico 7 (RJ 2012\199). 
comunicaciones, pero será el Constituyente de 1978 en que lo establezca como un derecho dotado de las mayores garantías constitucionales.

En la época dictatorial que tuvo lugar en España antes de la Constitución Española de 1978, las libertades de los ciudadanos eran muy limitadas, teniendo que tener cuidado con lo que se decía y dónde se decía, ya que se podían sufrir graves represalias por ello. Tras ésta época, la sociedad española quiere fervientemente una situación de estabilidad y anhela recuperar los derechos de los que se ha visto privados durante largo tiempo, y esto es lo que consigue el artículo 18.3 de la Carta Magna. Este artículo, consagra un derecho muy importante para la ciudadanía, de tal manera que el derecho al secreto de las comunicaciones va a suponer que cualquier persona puede comunicarse con otra, por la vía que desee, teniendo la tranquilidad de que nadie va a interferir en su mensaje. Evidentemente este derecho, que es muy amplio, no podía ser absoluto, de tal manera que se optó por limitarlo de la forma más adecuada posible, y es que únicamente se va a poder interferir en la comunicación cuando un juez lo permita y lo motive de forma concreta. De esta manera, los ciudadanos confían en que el poder judicial actuará correctamente tratando con máximo respeto el derecho constitucional, y los jueces van a tener la responsabilidad de actuar profesionalmente en el desempeño de sus funciones, siendo un éste un pacto implícito que es necesario para que la sociedad funcione.

\section{BIBLIOGRAFÍA}

Alonso Pérez, F., Intervención de las comunicaciones postales, telegráficas y telefónicas, Dykinson, Madrid, 2001.

Álvarez de Neyra Kappler, S., «Los descubrimientos casuales en el marco de una investigación penal (Con especial referencia a las diligencias de entrada y registro en domicilio)», Revista Internacional de Estudios de Derecho Procesal y Arbitraje, núm. 2, 2011.

De Llera SuÁreZ-BÁrcena, E., «El régimen jurídico ordinario de las observaciones telefónicas en el proceso penal», Poder Judicial, núm. 3.

DíAz Revorido, F. J., «El derecho fundamental al secreto de las comunicaciones», Derecho PUCP: Revista de la Facultad de Derecho, núm. 59, 2006.

FERNÁNDEZ LóPEZ, J. M., «Las inspecciones de las autoridades de la defensa de la competencia y los derechos de los inspeccionados», en: CASES, L. (Dir.), Anuario de la Competencia, Servei de Publicacions de la Universitat Autònoma de Barcelona, Bellaterra, 2010.

FERnÁNDEZ RodríGuez, J. J., Secreto e intervención de las comunicaciones en internet, Thomson Civitas, Madrid, 2004.

López-Barajas Perea, I., La intervención de las comunicaciones electrónicas, La Ley, Madrid, 2011.

LÓPEZ BARJA DE QUIROGA, J., Las escuchas telefónicas y la prueba ilegalmente obtenida, Akal Iure, Madrid, 1989. 
López-Fragoso Álvarez, T., Las intervenciones telefónicas en el proceso penal, Cólex, Madrid, 1991.

Martín Morales, R., El régimen constitucional del secreto de las comunicaciones, Civitas, Madrid, 1995.

Noya FerreIro, L., «Presupuestos constitucionales de las medidas de intervención de las comunicaciones I», Dereito. Revista xurídica da Universidade de Santiago de Compostela, vol. 8, núm. 2.

PAz Rubio, J. M., «La prueba en el proceso penal», Cuadernos de derecho Judicial, núm. 1, 1992.

RAMíRez MARTínez, A., Las intervenciones telefónicas en el derecho penal boliviano, Ariel Ramírez Martínez, Cochabamba, 2014.

Rebollo Delgado, L., «El secreto de las comunicaciones: problemas actuales», Revista de Derecho Político, núm. 48-49, 2000.

RODRÍGUEZ LAÍnZ, J. L., «En torno al concepto de comunicación protegida por el artículo 18.3 de la Constitución», Diario La Ley, núm. 8142, de 5 de septiembre de 2013.

Rodríguez Lainz, J. L. y Marchena Gómez, M., Estudios sobre el secreto de las comunicaciones. Perspectiva doctrinal y jurisprudencial, La Ley, Madrid, 2011.

Rodriguez Ruíz, B., El secreto de las comunicaciones: tecnología e intimidad, McGraw HiJi, Madrid, 1998.

SuÁRez Robledano, J. M., «Intervención de comunicaciones electrónicas», Foro: Revista de ciencias jurídicas y sociales, núm. 14, 2011.

\section{JURISPRUDENCIA}

STJCE de 18 de mayo de 1982 (asunto 155/79, AM \& S Europe Limited contra Comisión de las Comunidades Europeas) (ECLI:EU:C:1982:157).

STEDH de 28 de junio de 1984 (caso Campbell y Fell contra Reino Unido).

STEDH de 2 de noviembre de 1991 (caso S. contra suiza).

STEDH de 15 de noviembre de 1996 (caso Domenichini contra Italia).

STEDH de 25 de marzo de 1998 (caso Koop contra Suiza).

STEDH de 16 de febrero de 2000 (caso Amann contra Suiza).

STEDH de 1 de octubre de 2009 (caso Tsonyo Tsoney contra Bulgaria).

STC 114/1984, de 29 de noviembre.

STC 176/1988, de 4 de octubre.

STC 183/1994, de 20 de junio.

STC 58/1998, de 16 de marzo.

STC 166/1999 de 22 de febrero.

STC 49/1999 de 5 de abril.

STC 126/2000 de 16 de mayo.

STC $165 / 2005$ de 20 de junio.

STC 259/2005 de 24 de octubre.

STS 245/1995, de 6 de marzo (RJ 1995\1808).

ATS 756/1996, de 12 de mayo (RJ 1999\4976).

STS 538/1997, de 23 de abril (RJ 1997\3259). 
STS 320/1998, de 7 de marzo de 1998 (RJ 1998\2345).

STS 742/2002, de 24 de abril (RJ 2002\7338).

STS 510/2005, de 22 de abril, (RJ 2005\4315).

STS 1601/2005, de 22 de diciembre (RJ 2006\593).

STS 768/2010, de 15 de septiembre (RJ 2010\7823).

STS 79/2012, de 9 de febrero (RJ 2012\199).

STS 165/2013, de 26 de marzo (RJ 2013 \6412).

STS 551/2013, de 18 de junio (RJ 2013\8318).

STS 559/2014, de 8 de julio (RJ 2014\4025).

TITLE: Potential problems in the interception of communications in Spain.

RESUMEN: La intervención de las comunicaciones es una técnica de investigación muy en auge en los tiempos actuales, que en muchos casos permite, cuando procede su utilización, una mayor eficacia dentro del proceso penal, mas existen una serie de obstáculos o inconvenientes que pueden afectar a esta intervención, que es lo que se intenta resolver aquí, señalando cuáles son estos problemas y que mecanismos legales y jurisprudenciales existen para resolverlos.

PALABRAS CLAVE: Intervención de las comunicaciones - derechos fundamentales - secreto de las actuaciones.

ABSTRACT: The interception of communications is a investigation technique that it is booming at the present, in manu cases this technique this allows you to obtain more effectively in criminal proceedings, but exists a series of elements that could affect the investigation, thar it is to try resolve here, by outlining the main problems and that legal and jurisprudential mechanisms exists for resolving them.

KEYWORDS: Interception of communications - fundamental rigths - secrecy of proceedings. 